\title{
Observed Data Containing One Parameter and Chance Error: Probabilistic Evaluation of Parameter by Pythagorean Mean
}

\author{
Dhritikesh Chakrabarty \\ Department of Statistics, Handique Girls' College, Guwahati, Assam, India, \\ dhritikesh.c@rediffmail.com,dhritikeshchakrabarty@gmail.com
}

\begin{abstract}
Recently some methods have been developed for determining the appropriate value of the parameter from observed data containing the parameter itself and chance error since the existing statistical methods of estimation in such situation fail in finding out the appropriate value of the parameter. However, the methods are based on some probabilistic assumptions. Accordingly, the value of the parameter obtained by the methods is not deterministic but probabilistic i.e. one cannot be fully certain that the value of the parameter obtained is identical with its actual value. This paper is based on the evaluation of the probability that the value obtained is the actual value of the parameter and on one numerical application of the method in determining the central tendency of each of annual maximum and annual minimum of ambient air temperature at Guwahati.
\end{abstract}

Key words: 1; Observed data 2; parameter 3; chance error 4; probabilistic evaluation of parameter

\section{Introduction:}

There are many situations where observed data

$$
x_{1}, x_{2}, \ldots \ldots \ldots \ldots, x_{n}
$$

are composed of some parameter $\mu$ and chance errors $\varepsilon_{i}$ i.e.

$$
x_{i}=\mu+\varepsilon_{i}, \quad(i=1,2, \ldots \ldots \ldots, n)
$$

[Chakrabarty $(2014 a, 2014 b, 2014 c, 2015 a, 2015 b, 2015 c, 2015 d, 2015 e$ ]. The existing methods of estimation of $\mu$ namely least squares method, maximum likelihood method, minimum variance unbiased method, method of moment and method of minimum chi-square, [Aldrich (1930), Anders (1999), 
Barnard (1949), Birnbaum (1962), Ivory (1825), Kendall \& Stuart (1977), Lehmann \& Casella George (1998), Lucien (1990), Walker \& Lev (1965)]

provides $\bar{X}$ as estimator of the parameter $\mu$ where $\bar{X}$ is given by

$$
\bar{X}=\frac{1}{n} \sum_{\mathrm{i}=1}^{n} x_{i}
$$

It has been shown that this estimator $\bar{X}$ of the parameter $\mu$ suffers from an error $\bar{\varepsilon}$ given by

$$
\bar{\varepsilon}=\frac{1}{n} \sum_{i=1}^{n} \varepsilon_{i}
$$

which is not zero usually. In other words, none of these methods can provide appropriate value of the parameter $\mu$ [Chakrabarty $(2014 a, 2014 b, 2014 c)]$.

Recently, some studies have been done on determining the true value of the parameter $\mu$ involved in the model described by (1.1) [Chakrabarty $(2014 a, 2014 b, 2014 c, 2015 a, 2015 b, 2015 c, 2015 d$, 2015e , 2015f , 2016a , 2016b) , Bordoloi \& Chakrabarty (2015 , $2015-16$, 2016a , 2016b , 2016c , 2016 - 17)]. In these studies some methods have been developed for determining the true value of the parameter $\mu$ when $\varepsilon_{i}$ occurs due to chance only. One of them is based on computing sequence of interval value of $\mu$ with decreasing length of interval and then to find out the shortest interval value of $\mu$ [Chakrabarty $(2014 a, 2014 b, 2014 c, 2015 d)$, Bordoloi \& Chakrabarty $(2016 a, 2016 b$ ]. The other one is based on stable mid range and median. However, these methods may not be always successful in determining the true value $\mu$ [Chakrabarty (2015b), Bordoloi \& Chakrabarty (2015)]. For this reason, another method has been derived for determining the true value $\mu$ which is based on the convergence of statistic i.e. some function of the available numerical data (Chakrabarty , 2017). However, in some situations, the available data may not be sufficient obtaining the converging point of the statistic considered. One method has been developed for determining the true value $\mu$ in such situation (Chakrabarty, 2018a). The method is based on the Pythagorean means [Kolmogorov (1930), O'Meara (1989), Riedweg (2005), Cornelli, McKirahan \& Macris (2013), de Carvalho (2016), Chakrabarty (2018b, $2018 c, 2018 d, 2018 e)]$. The methods, developed so far, for determining the appropriate value of the parameter from observed data containing the parameter itself and chance error are based on some probabilistic assumptions. Accordingly, the value of the parameter obtained by the methods is not 
deterministic but probabilistic i.e. one cannot be fully certain that the value of the parameter obtained is identical with its actual value. This paper is based on the evaluation of the probability that the value obtained is the actual value of the parameter and on one numerical application of the method in determining the central tendency of each of annual maximum and annual minimum of ambient air temperature at Guwahati.

\section{Probabilistic Evaluation of $\mu$ :}

\subsection{Probabilistic Convergence of Pythagorean Arithmetic Mean of Observations}

If the observations

$$
x_{1}, x_{2}, \ldots \ldots \ldots ., x_{n}
$$

are composed of some parameter $\mu$ and chance errors then the observations can be expressed as

$$
x_{i}=\mu+\varepsilon_{i} \quad, \quad(i=1,2, \ldots \ldots \ldots, n)
$$

where

(i) $x_{1}, x_{2}, \ldots \ldots \ldots . ., x_{n}$ are observed data,

(ii) $\mu$ is the parameter

\& (iii) $\varepsilon_{1}, \varepsilon_{2}, \ldots \ldots \ldots . ., \varepsilon_{n}$ are the chance errors associated to

$$
x_{1}, x_{2}, \ldots \ldots \ldots \ldots, x_{n}
$$

respectively which assume positive and negative values in random order.

From Equations described by (2.1),

$$
\sum_{i=1}^{n} x_{i}=n \mu+\sum_{i=1}^{n} \varepsilon_{i}
$$

which implies

$$
A\left(x_{1}, x_{2}, \ldots . . . . . ., x_{n}\right)=\mu+A\left(\varepsilon_{1}, \varepsilon_{2}, \ldots . . . . ., \varepsilon_{n}\right)
$$

where

$$
\begin{aligned}
& A\left(x_{1}, x_{2}, \ldots . \ldots \ldots . ., x_{n}\right)=\frac{1}{n} \sum_{i=1}^{n} x_{\mathrm{i}} \\
\& \quad & A\left(\varepsilon_{1}, \varepsilon_{2}, \ldots . . . \ldots . ., \varepsilon_{n}\right)=\frac{1}{n} \sum_{i=1}^{n} \varepsilon_{i}
\end{aligned}
$$

Now,

$$
\varepsilon_{1}, \varepsilon_{2}, \ldots \ldots \ldots \ldots, \varepsilon_{n}
$$


are independently and identically distributed random variables with arithmetic expectation zero (0). Therefore by the law of large numbers, the series

$$
\left\{A_{n}(\varepsilon)=A\left(\varepsilon_{1}, \varepsilon_{2}, \ldots \ldots \ldots . . . \varepsilon_{n}\right)=\frac{1}{n} \sum_{i=1}^{n} \varepsilon_{i}\right\}
$$

converges to 0 with probability approaching 1 that is with probability approaching certainity as $n \rightarrow \infty$. Accordingly with probability approaching 1 that is with probability approaching certainity, the series

$$
\left\{A_{n}(x)=A\left(\varepsilon_{1}, \varepsilon_{2}, \ldots \ldots \ldots . . ., \varepsilon_{n}\right)=\frac{1}{n} \sum_{i=1}^{n} x_{i}\right\}
$$

converges to $\mu$ as $n \rightarrow \infty$.

Note (2.1.1): Since

$$
\varepsilon_{1}, \varepsilon_{2}, \ldots \ldots \ldots ., \varepsilon_{n}
$$

are random, each of them can assume either positive value or negative value with equal probability i.e.

$$
P\left(\varepsilon_{i}<0\right)=P\left(\varepsilon_{i}>0\right)=1 / 2 \text { for all } i=1,2, \ldots \ldots \ldots, n
$$

This implies, the probability that all of them assume positive values is $(1 / 2)^{n}$.

Similarly, the probability that all of them assume negative values is $(1 / 2)^{n}$.

Therefore, the probability that all of them assume values with same sign is $(1 / 2)^{n}+(1 / 2)^{n}=(1 / 2)^{n-1}$.

The series $\left\{A_{n}(\varepsilon)\right\}$ will never converge to 0 if all

$$
\varepsilon_{1}, \varepsilon_{2}, \ldots \ldots \ldots ., \varepsilon_{n}
$$

assume values with same sign

and hence the series $\left\{A_{n}(x)\right\}$ will never converge to $\mu$ with probability $(1 / 2)^{n-1}$ i.e. the converging point of the series $\left\{A_{n}(x)\right\}$, if exits, is not the actual value of $\mu$ with probability $(1 / 2)^{n-1}$.

\subsection{Probabilistic Convergence of Pythagorean Geometric Mean of Observations}

If the observations

$$
x_{1}, x_{2}, \ldots \ldots \ldots \ldots, x_{n}
$$

are composed of some parameter $\mu$ and chance errors then the observations can also be expressed as

$$
x_{i}=\mu . e_{i}, \quad(i=1,2, \ldots \ldots \ldots ., n)
$$

where 


$$
e_{1}, e_{2}, \ldots \ldots \ldots . ., e_{n}
$$

are the chance errors associated to

$$
x_{1}, x_{2}, \ldots \ldots \ldots ., x_{n}
$$

respectively assuming positive values either pure decimal fraction or greater than 1 occurred in random order.

From Equations described by (2.6),

$$
\left(\prod_{i=1}^{n} x_{i}\right)^{1 / n}=\mu \cdot\left(\prod_{i=1}^{n} e_{i}\right)^{1 / n}
$$

which implies

$$
G\left(x_{1}, x_{2}, \ldots . . . . . ., x_{n}\right)=\mu . G\left(e_{1}, e_{2}, \ldots . . \ldots . ., e_{n}\right)
$$

where

$$
\begin{aligned}
G\left(x_{1}, x_{2}, \ldots . . . . . ., x_{n}\right) & =\left(\prod_{i=1}^{n} x_{i}\right)^{1 / n} \\
\& G\left(e_{1}, e_{2}, \ldots . . . . . ., e_{n}\right) & =\left(\prod_{i=1}^{n} e_{i}\right)^{1 / n}
\end{aligned}
$$

Now,

$$
e_{1}, e_{2}, \ldots \ldots \ldots ., e_{n}
$$

are independently and identically distributed random variables with geometric expectation one (1).

Therefore by the similar logic of the law of large numbers, the series

$$
\left\{G_{n}(e)=G\left(e_{1}, e_{2}, \ldots . . . . . ., e_{n}\right)=\left(\prod_{i=1}^{n} e_{i}\right)^{1 / n}\right\}
$$

converges to 1 with probability approaching 1 as $n \rightarrow \infty$.

Accordingly, with probability approaching certainity, the series

$$
\left\{G_{n}(x)=G\left(x_{1}, x_{2}, \ldots . . \ldots . ., x_{n}\right)=\left(\prod_{i=1}^{n} x_{i}\right)^{1 / n}\right\}
$$

converges to $\mu$ as $n \rightarrow \infty$.

Note (2.2.1): Since

$$
e_{1}, e_{2}, \ldots \ldots \ldots . ., e_{n}
$$

are random, each of them can assume positive values either pure decimal fraction and greater than 1 with equal probability i.e.

$$
P\left(0<e_{i}<1\right)=P\left(e_{i}>1\right)=1 / 2 \text { for all } i=1,2, \ldots \ldots \ldots, n
$$


This implies, the probability that all of them assume values in $0<e_{i}<1$ is $(1 / 2)^{n}$.

Similarly, the probability that all of them assume values in $e_{i}>1$ is $(1 / 2)^{n}$.

Therefore, the probability that all of them assume values of same type is $(1 / 2)^{n}+(1 / 2)^{n}=(1 / 2)^{n-1}$.

Now, the series $\left\{G_{n}(e)\right\}$ will never converge to 1 if all

$$
\varepsilon_{1}, \varepsilon_{2}, \ldots \ldots \ldots ., \varepsilon_{n}
$$

assume values of same type

and hence the series $\left\{G_{n}(e)\right\}$ will never converge to $\mu$ with probability $(1 / 2)^{n-1}$ i.e. the converging point of the series $\left\{G_{n}(e)\right\}$, if exits, is not the actual value of $\mu$ with probability $(1 / 2)^{n-1}$.

\subsection{Evaluation of $\mu$}

Each of the the two series given by (2.5) \& (2.10) converges to $\mu$ as $n \rightarrow \infty$ with probability approaching 1(i.e. with probability approaching certainity).

Therefore, in order to determine the value of $\mu$, it is required to compute the converging values of the two series

$$
\begin{gathered}
\left\{A_{n}(x)=A\left(\varepsilon_{1}, \varepsilon_{2}, \ldots \ldots \ldots \ldots, \varepsilon_{n}\right)=\frac{1}{n} \sum_{i=1}^{n} x_{i}\right\} \\
\& \quad\left\{G_{n}(x)=G\left(x_{1}, x_{2}, \ldots \ldots \ldots . ., x_{n}\right)=\left(\prod_{i=1}^{n} x_{i}\right)^{1 / n}\right\}
\end{gathered}
$$

The common value of them is the actual value of $\mu$ with probability approaching 1(i.e. with probability approaching certainity) and is not the actual value of $\mu$ with probability $(1 / 2)^{n-1}$ where $n$ is the number of observations.

Note (2.3.1): If the series is found to converge but fail to yield a common converging point for the available data then it is to be understood that the available data are insufficient for obtaining the value of $\mu$.

Note (2.3.2): If the series is found either not to converge or to converge to different points then it is to be understood that the errors involved in the data are not only due to chance but also due to some assignable cause(s). Consequently, the data do not follow the model described by the equation (2.1). Accordingly, the value of $\mu$ cannot be determined from the given data in this case.

Note (2.3.3): From (2.6), 


$$
\log G\left(x_{1}, x_{2}, \ldots \ldots \ldots \ldots, x_{n}\right)=\frac{1}{n} \sum_{i=1}^{n} \log x_{i}
$$

which yields,

$$
G\left(x_{1}, x_{2}, \ldots \ldots \ldots \ldots, x_{n}\right)=\operatorname{antilog}\left\{\frac{1}{n} \sum_{i=1}^{n} \log x_{i}\right\}
$$

This formula can be applied in computing the values of the series given by (2.10) since its computation by

$$
G\left(x_{1}, x_{2}, \ldots \ldots \ldots . ., x_{n}\right)=\left(\prod_{i=1}^{n} x_{i}\right)^{1 / n}
$$

is too complicated.

\section{Application to Numerical Data:}

Observed data considered here are the data on each of annual maximum \& annual minimum of ambient air temperature, occurred in temperature periodic year (TPR), at Guwahati during the period from 1969 to 2013. The objective here is to evaluate, with probability approaching certainity, the central tendency of each of annual maximum \& annual minimum of ambient air temperature at Guwahati

\subsection{Annual Maximum of Ambient Air Temperature at Guwahati:}

The following table shows the observed data on annual maximum of ambient air temperature, occurred in temperature periodic year (TPR), at Guwahati during the period from 1969 to 2013:

Table-3.1.1

Observed Value on Annual Maximum of Ambient Air Temperature (in Degree Celsius)

\begin{tabular}{|c|c|c|c|c|c|c|c|}
\hline $\begin{array}{c}\text { TPR No } \\
(i)\end{array}$ & $\begin{array}{c}\text { Observed } \\
\text { Value }\left(x_{i}\right)\end{array}$ & $\begin{array}{c}\text { TPR No } \\
(i)\end{array}$ & $\begin{array}{c}\text { Observed } \\
\text { Value }\left(X_{i}\right)\end{array}$ & $\begin{array}{c}\text { TPR No } \\
(i)\end{array}$ & $\begin{array}{c}\text { Observed } \\
\text { Value }\left(x_{i}\right)\end{array}$ & $\begin{array}{c}\text { TPR No } \\
(i)\end{array}$ & $\begin{array}{c}\text { Observed } \\
\text { Value }\left(X_{i}\right)\end{array}$ \\
\hline 1 & 37.1 & 12 & 35.1 & 23 & 37.4 & 34 & 38.0 \\
\hline 2 & 36.6 & 13 & 35.8 & 24 & 39.4 & 35 & 36.6 \\
\hline 3 & 36.0 & 14 & 36.5 & 25 & 36.4 & 36 & 38.0 \\
\hline 4 & 35.7 & 15 & 36.7 & 26 & 38.1 & 37 & 37.3 \\
\hline 5 & 39.0 & 16 & 37.2 & 27 & 36.3 & 38 & 37.3 \\
\hline 6 & 36.1 & 17 & 36.5 & 28 & 39.9 & 39 & 38.0 \\
\hline
\end{tabular}


International Journal of Electronics and Applied Research (IJEAR) vol. 6, issue 1, June 2019 Online (http://eses.net.in/online_journal.html)

\begin{tabular}{|l|l|l|l|l|l|l|l|}
\hline 7 & 39.2 & 18 & 38.4 & 29 & 37.4 & 40 & 37.2 \\
\hline 8 & 39.0 & 19 & 37.2 & 30 & 37.5 & 41 & 37.3 \\
\hline 9 & 35.3 & 20 & 36.4 & 31 & 36.7 & 42 & 37.4 \\
\hline 10 & 36.8 & 21 & 36.7 & 32 & 35.7 & 43 & 38.8 \\
\hline 11 & 38.6 & 22 & 36.0 & 33 & 37.4 & & \\
\hline
\end{tabular}

Here the observed values $x_{i}(i=1,2,3$, 43) can be assumed to be composed of a parameter $\mu$ (representing the central tendency of annual maximum) and chance errors.

\subsection{Evaluation of Value of $\mu$ (the central tendency of annual maximum)}

The computed values of $A_{n}=A\left(x_{1}, x_{2}, \ldots . . \ldots . ., x_{n}\right) \& G_{n}=G\left(x_{1}, x_{2}, \ldots . \ldots \ldots, x_{n}\right)$ have been shown in Table-3.1.2.

In Table-3.1.2, it is found that the values of $A_{n}=A\left(x_{1}, x_{2}, \ldots \ldots \ldots ., x_{n}\right)$ and $G_{n}=G\left(x_{1}, x_{2}\right.$, ,$\left.x_{n}\right)$ are approaching 37.2

Hence, with probability approaching 1 , the value of the central tendency of annual maximum of the ambient air temperature at Guwahati can be taken as 37.2 Degree Celsius.

However, 37.2 Degree Celsius cannot be the actual value of the central tendency with probability

$$
(1 / 2)^{42}=2.273736754 \times 10^{-13}
$$

Table-3.1.2

\begin{tabular}{|c|c|c|c|}
\hline $\begin{array}{c}\text { TPR No } \\
(n)\end{array}$ & Value of & TPR No & Value of \\
\hline 1 & $A_{n}=A\left(x_{1}, x_{2}, \ldots \ldots \ldots, x_{n}\right)$ & $(n)$ & $A_{n}=A\left(x_{1}, x_{2}, \ldots \ldots \ldots, x_{n}\right)$ \\
\hline 2 & 37.1 & 23 & 36.92608695652174 \\
\hline 3 & 36.85 & 24 & 37.02916666666667 \\
\hline 4 & 36.56666666666667 & 25 & 37.004 \\
\hline 5 & 36.35 & 26 & 37.04615384615385 \\
\hline 6 & 36.88 & 27 & 37.01851851851852 \\
\hline 7 & 36.75 & 28 & 37.12142857142857 \\
\hline
\end{tabular}


International Journal of Electronics and Applied Research (IJEAR) vol. 6, issue 1, June 2019

\begin{tabular}{|l|c|c|c|}
\hline 8 & 37.3375 & 30 & 37.14333333333333 \\
\hline 9 & 37.11111111111111 & 31 & 37.12903225806452 \\
\hline 10 & 37.08 & 32 & 37.084375 \\
\hline 11 & 37.21818181818182 & 33 & 37.09393939393939 \\
\hline 12 & 37.04166666666667 & 34 & 37.12058823529412 \\
\hline 13 & 36.94615384615385 & 35 & 37.10571428571429 \\
\hline 14 & 39.75492307692308 & 36 & 37.13055555555556 \\
\hline 15 & 36.9 & 37 & 37.13513513513514 \\
\hline 16 & 36.91875 & 38 & 37.13947368421053 \\
\hline 17 & 36.89411764705882 & 39 & 37.16153846153846 \\
\hline 18 & 36.97777777777778 & 40 & 37.1625 \\
\hline 19 & 36.98947368421053 & 41 & 37.16585365853659 \\
\hline 20 & 36.96 & 42 & 37.17142857142857 \\
\hline 21 & 36.94761904761905 & 43 & 37.2093023255814 \\
\hline 22 & 36.90454545454545 & & \\
\hline
\end{tabular}

Table-3.1.3

\begin{tabular}{|c|c|c|c|}
\hline $\begin{array}{c}\text { TPR } \\
\text { No }\end{array}$ & $G_{n}=G\left(x_{1}, x_{2}, \ldots \ldots \ldots \ldots, x_{n}\right)$ & TPR & Value of \\
$(n)$ & No & $G_{n}=G\left(x_{1}, x_{2}, \ldots \ldots \ldots \ldots, x_{n}\right)$ \\
\hline 1 & 37.100000000000000000000000000001 & 23 & 36.907951375530228273997704899203 \\
\hline 2 & 36.849151957677397816492457471162 & 24 & 37.008568334146486997509657949442 \\
\hline 3 & 36.563898828796401481877921649392 & 25 & 36.984031371155694976981399533444 \\
\hline 4 & 36.345983740858013867930065117099 & 26 & 37.0263425952267435557691601271825 \\
\hline 5 & 36.861929466436019045199560948853 & 27 & 36.999183617772609404713638815137 \\
\hline 6 & 36.733833524906529592733500969237 & 28 & 37.099058031246057185229984821213 \\
\hline 7 & 37.0764082377795822974496661223967 & 29 & 37.1093949169815777631613488308734 \\
\hline 8 & 37.311570055521037921393145135076 & 30 & 37.122349300390835138945562995519 \\
\hline 9 & 37.082517567449318065559488651693 & 31 & 37.108649562396908895644952409924 \\
\hline 10 & 37.054168483041978324085190136495 & 32 & 37.063799115887290185156645453858 \\
\hline
\end{tabular}


International Journal of Electronics and Applied Research (IJEAR) vol. 6, issue 1, June 2019 Online (http://eses.net.in/online_journal.html)

ISSN 2395-0064

\begin{tabular}{|l|l|l|l|}
\hline 11 & 37.192102443715679881528536182712 & 33 & 37.073942480150612130026293039573 \\
\hline 12 & 37.013097252648824947218023353606 & 34 & 37.10085461802179646288605030756 \\
\hline 13 & 36.918340130784241941575383015056 & 35 & 37.0864498129419154156748278045 \\
\hline 14 & 36.888300330268507049140494882929 & 36 & 37.111527173121534380089866586791 \\
\hline 15 & 36.875716972191085058307452585677 & 37 & 37.116608490052709885185023589966 \\
\hline 16 & 36.895901586189937568294003784643 & 38 & 37.121423011021134475117582568853 \\
\hline 17 & 36.872494839717900572818157696334 & 39 & 37.143694849862191868851959925933 \\
\hline 18 & 36.955739386544954474314437641907 & 40 & 37.145101439431196544614817207745 \\
\hline 19 & 36.968555130673424804462730928845 & 41 & 37.148871788937429088904002963936 \\
\hline 20 & 36.939917603077075159918808821998 & 42 & 37.154831390672328678435909684177 \\
\hline 21 & 36.928457471495227871573252621182 & 43 & 37.192287148576076781925812747586 \\
\hline 22 & 36.885739991394209779636891882147 & & \\
\hline
\end{tabular}

\subsection{Annual Minimum of Ambient Air Temperature at Guwahati:}

The following table (Table-3.2.1) shows the observed data on annual maximum of ambient air temperature, occurred in temperature periodic year (TPR), at Guwahati during the period from1969 to 2013.

As earlier, the observed values

$$
x_{i}(i=1,2,3 \text {, }
$$

can in this case also be assumed to be composed of a parameter $\mu$ (representing the central tendency of annual minimum) and chance errors.

\section{Table-3.2.1}

Observed Value on Annual Minimum of Ambient Air Temperature (in Degree Celsius)

\begin{tabular}{|c|c|c|c|c|c|c|c|}
\hline $\begin{array}{l}\text { TPR No } \\
\text { (i) }\end{array}$ & $\begin{array}{l}\text { Observed } \\
\text { Value }\left(x_{i}\right)\end{array}$ & $\begin{array}{c}\text { TPR No } \\
\text { (i) }\end{array}$ & $\begin{array}{c}\text { Observed } \\
\text { Value }\left(X_{i}\right)\end{array}$ & $\begin{array}{c}\text { TPR No } \\
\text { (i) }\end{array}$ & $\begin{array}{l}\text { Observed } \\
\text { Value }\left(x_{i}\right)\end{array}$ & $\begin{array}{c}\text { TPR No } \\
\text { (i) }\end{array}$ & $\begin{array}{c}\text { Observed } \\
\text { Value }\left(X_{i}\right)\end{array}$ \\
\hline 1 & 6.6 & 12 & 7.5 & 23 & 5.9 & 34 & 8.0 \\
\hline 2 & 5.9 & 13 & 8.3 & 24 & 8.4 & 35 & 7.9 \\
\hline 3 & 8.2 & 14 & 4.9 & 25 & 7.8 & 36 & 6.7 \\
\hline 4 & 5.0 & 15 & 6.1 & 26 & 7.5 & 37 & 9.6 \\
\hline
\end{tabular}


International Journal of Electronics and Applied Research (IJEAR) vol. 6, issue 1, June 2019 Online (http://eses.net.in/online_journal.html)

\begin{tabular}{|l|l|l|l|l|l|l|l|}
\hline 5 & 6.3 & 16 & 7.8 & 27 & 9.4 & 38 & 6.4 \\
\hline 6 & 7.4 & 17 & 8.6 & 28 & NA & 39 & 7.8 \\
\hline 7 & 6.6 & 18 & 7.7 & 29 & NA & 40 & 9.9 \\
\hline 8 & 6.2 & 19 & 9.2 & 30 & NA & 41 & 8.6 \\
\hline 9 & 7.3 & 20 & 6.7 & 31 & 8.3 & 42 & 7.0 \\
\hline 10 & 6.2 & 21 & 8.6 & 32 & 8.9 & 43 & 6.4 \\
\hline 11 & 6.4 & 22 & 7.4 & 33 & 8.6 & 44 & 5.6 \\
\hline
\end{tabular}

\subsection{Determination of Value of $\boldsymbol{\mu}$ (the central tendency of annual minimum)}

The computed values of

$$
A_{n}=A\left(x_{1}, x_{2}, \ldots \ldots \ldots . ., x_{n}\right) \text { and } G_{n}=G\left(x_{1}, x_{2}, \ldots \ldots \ldots ., x_{n}\right)
$$

have been shown in Table-3.2.2.

In Table-3.2.2, it is found that the values of

$$
A_{n}=A\left(x_{1}, x_{2}, \ldots . \ldots \ldots, x_{n}\right) \text { and } G_{n}=G\left(x_{1}, x_{2}, \ldots \ldots \ldots . x_{n}\right)
$$

are not approaching a common value.

Thus, either the data are insufficient to yield the true value of the central tendency of annual minimum of the ambient air temperature at Guwahati or the data do not follow the model described by equation (2.1).

Table-3.2.2

\begin{tabular}{|c|c|c|c|}
\hline $\begin{array}{c}\text { TPR } \\
\text { No } \\
(n)\end{array}$ & $\begin{array}{c}\text { Values of } \\
A_{n}=A\left(x_{1}, x_{2}, \ldots \ldots \ldots . .\right. \\
\left., x_{n}\right)\end{array}$ & $\begin{array}{c}\text { TPR } \\
\text { No } \\
(n)\end{array}$ & $\begin{array}{c}\text { Values of } \\
A_{n}=A\left(x_{1}, x_{2}, \ldots \ldots \ldots \ldots\right. \\
\left., x_{n}\right)\end{array}$ \\
\hline 1 & 6.6 & 23 & 7.021739130434783 \\
\hline 2 & 6.6 & 24 & 6.975 \\
\hline 3 & 6.366666666666667 & 25 & 7.032 \\
\hline 4 & 6.825 & 26 & 7.061538461538462 \\
\hline 5 & 6.46 & 27 & 7.077777777777778 \\
\hline 6 & 6.433333333333333 & 28 & 7.160714285714286 \\
\hline 7 & 6.571428571428571 & 29 & 7.220689655172414 \\
\hline 8 & 6.575 & 30 & 7.266666666666667 \\
\hline
\end{tabular}


International Journal of Electronics and Applied Research (IJEAR) vol. 6, issue 1, June 2019 Online (http://eses.net.in/online_journal.html)

ISSN 2395-0064

\begin{tabular}{|c|c|c|c|}
\hline 9 & 6.533333333333333 & 31 & 7.290322580645161 \\
\hline 10 & 6.61 & 32 & 7.309375 \\
\hline 11 & 6.572727272727273 & 33 & 7.290909090909091 \\
\hline 12 & 6.558333333333333 & 34 & 7.358823529411765 \\
\hline 13 & 6.630769230769231 & 35 & 7.331428571428571 \\
\hline 14 & 6.75 & 36 & 7.344444444444444 \\
\hline 15 & 6.626666666666667 & 37 & 7.413513513513514 \\
\hline 16 & 6.59375 & 38 & 7.444736842105263 \\
\hline 17 & 6.664705882352941 & 39 & 7.433333333333333 \\
\hline 18 & 6.772222222222222 & 40 & 7.4075 \\
\hline 19 & 6.821052631578947 & 41 & 7.363414634146341 \\
\hline 20 & 6.94 & 42 & 7.021739130434783 \\
\hline 21 & 6.928571428571429 & 43 & 6.975 \\
\hline 22 & 7.004545454545455 & 44 & 7.032 \\
\hline
\end{tabular}

Table-3.2.3

\begin{tabular}{|c|c|c|c|}
\hline $\begin{array}{c}\text { TPR } \\
\text { No } \\
(n)\end{array}$ & $G_{n}=G\left(x_{1}, x_{2}, \ldots \ldots \ldots \ldots, x_{n}\right)$ & $\begin{array}{c}\text { TPR } \\
\text { No } \\
(n)\end{array}$ & $G_{n}=G\left(x_{1}, x_{2}, \ldots \ldots \ldots \ldots, x_{n}\right)$ \\
\hline 1 & 6.6000000000000000000000000000002 & 23 & 6.8994798638029492332170025993497 \\
\hline 2 & 6.2401923047290778184540741626669 & 24 & 6.9562840436945652525470112265315 \\
\hline 3 & 6.8349697977658553153553991473341 & 25 & 6.9882108302873798619833480810597 \\
\hline 4 & 6.3211333313459467749216627042232 & 26 & 7.0072334421441164904282182533205 \\
\hline 5 & 6.3169010013367452786283625052215 & 27 & 7.0838901531221111364268314501887 \\
\hline 6 & 6.4857272185701169855041242093667 & 28 & 7.1240865180443321452583935939618 \\
\hline 7 & 6.5019299609413096599434266552134 & 29 & 7.1789729488032751962564480429371 \\
\hline 8 & 6.4633989337912701904703289281854 & 30 & 7.2223221258860362445338145542488 \\
\hline 9 & 6.5514058846887191769812286015146 & 31 & 7.2461869803895066094818774956424 \\
\hline 10 & 6.5153871170191872914459649178302 & 32 & 7.2657752520059477722135734563005 \\
\hline 11 & 6.5048119729138514238168851259175 & 33 & 7.247948125913456784586179510479 \\
\hline 12 & 6.5824407269348502376566800461569 & 34 & 7.3081081108055937176215071779575 \\
\hline 13 & 6.7008890789412278622783766593454 & 35 & 7.2804552217016962246905047234237 \\
\hline
\end{tabular}


International Journal of Electronics and Applied Research (IJEAR) vol. 6, issue 1, June 2019 Online (http://eses.net.in/online_journal.html)

ISSN 2395-0064

\begin{tabular}{|l|l|l|l|}
\hline 14 & 6.5527362805560146596136072863623 & 36 & 7.2944086947827372183189849879502 \\
\hline 15 & 6.5215350514733093207287599447551 & 37 & 7.3548715998389568402950960158236 \\
\hline 16 & 6.5949101184036978619969386660223 & 38 & 7.8154612929430738975137961946202 \\
\hline 17 & 6.6987014182595463410514031559311 & 39 & 7.7934100068228333088588686838578 \\
\hline 18 & 6.7507455267102729305100790423158 & 40 & 7.7551256022354259620074788758758 \\
\hline 19 & 6.8616303970395831831869394230887 & 41 & 7.6937848209202825772540315655963 \\
\hline 20 & 6.8534570444635167207666214239384 & 42 & 6.8994798638029492332170025993497 \\
\hline 21 & 6.9279444662370421736229802749321 & 43 & 6.9562840436945652525470112265315 \\
\hline 22 & 6.9487332418478471976809533313006 & 44 & 6.9882108302873798619833480810597 \\
\hline
\end{tabular}

Note: Data corresponding to TPR 29, $30 \& 31$ are not available. Therefore, the values of

$$
A_{n}=A\left(x_{1}, x_{2}, \ldots . \ldots \ldots, x_{n}\right) \text { and } G_{n}=G\left(x_{1}, x_{2}, \ldots . \ldots \ldots, x_{n}\right)
$$

could not be computed corresponding these three TPR.

\section{Conclusion:}

The method, developed here, can provide the value of the parameter if the data follow the model described by equation (2.1) and if the data size is sufficiently large for obtaining the common converging point of $A_{n}=A\left(x_{1}, x_{2}, \ldots . \ldots \ldots, x_{n}\right)$ and $G_{n}=G\left(x_{1}, x_{2}, \ldots \ldots \ldots . ., x_{n}\right)$. Conversely, if the common converging point of $A_{n}=A\left(x_{1}, x_{2}, \ldots . \ldots \ldots, x_{n}\right)$ and $G_{n}=G\left(x_{1}, x_{2}\right.$, ,$\left.x_{n}\right)$ is not achieved from the set of data then it implies that either the data do not follow the model described by equation (2.1) or the data size is not sufficient to yield the common converging point.

Regarding the findings obtained on annual maximum and annual minimum of ambient air temperature at Guwahati, the following conclusion can be drawn:

4.1. The central tendency of Annual Maximum of Ambient Air Temperature at Guwahati can be taken as 37.2 Degree Celsius, with probability approaching 1 (i.e. with probability certainity), since all the methods applied have yielded the same numerical results and thus the corresponding data can be treated to follow the model described by equation (2.1).

4.2. The central tendency of Annual Minimum of Ambient Air Temperature at Guwahati is not determinable since the methods applied have yielded different numerical results and thus the corresponding data cannot be treated to follow the model described by equation (2.1). 
In this connection, it is to be mentioned that the central tendency of each of annual maximum and annual minimum of the ambient air temperature at Guwahati has been evaluated by another method already developed (Chakrabarty , 2017). The findings obtained by that method have been found to be identical with the findings obtained by the method developed here.

\section{References:}

Anders Hald, On the History of Maximum Likelihood in Relation to Inverse Probability and Least Squares, Statistical Science, Vol. 14, pp. 214 - 222, 1999.

Aldrich John, Fisher's Inverse Probability of 1930, International Statistical Review, Vol. 68, pp. 155 $172,2000$.

Barnard G. A., Statistical Inference, Journal of the Royal Statistical Society, Series B, Vol. 11, pp. 115 149, 1949.

Bordoloi Rinamani Sarmah \& Chakrabarty Dhritikesh, Central Tendency of Annual Extremum of Ambient Air Temperature at Tezpur Based on Midrange and Median, J. Chem. Bio. Phy. Sci. (E- ISSN : 2249 - 1929), Sec. C, 5(4), 4397 - 4410, 2015.

Bordoloi Rinamani Sarmah \& Chakrabarty Dhritikesh, Annual Extremum of Ambient Air Temperature at Dibrugarh: Determination of Central Tendency, J. Chem. Bio. Phy. Sci. (E- ISSN : 2249 - 1929), Sec. D, $6(1), 212-233,2015-16$.

Bordoloi Rinamani Sarmah \& Chakrabarty Dhritikesh, Determination of Parameter from Observation Containing Itself and Chance Error: Central Tendency of Ambient Air Temperature at Tezpur, International Journal of Advanced Research in Science, Engineering and Technology, (ISSN : $2350-$ 0328), 3(1), $1202-1213,2016 a$.

Bordoloi Rinamani Sarmah \& Chakrabarty Dhritikesh, Determination of Parameter from Observation Containing Itself and Chance Error: Central Tendency of Ambient Air Temperature at Dibrugarh, International Journal of Advanced Research in Science, Engineering and Technology, (ISSN : 2350 0328), 3(8), $2488-2500,2016 b$.

Bordoloi Rinamani Sarmah and Chakrabarty Dhritikesh, Confidence Interval of Annual Extremum of Ambient Air Temperature at Guwahati, Journal of Mathematics and Systems Sciences (ISSN : 0975 5454), 12(1-2), 55-62, $2016 c$.

Bordoloi Rinamani Sarmah \& Chakrabarty Dhritikesh, Determination of Parameter from Observation Containing itself and Chance Error: Central Tendency of Annual Extremum of Ambient Air Temperature at Dhubri, J. Chem. Bio. Phy. Sci. (E- ISSN : 2249 - 1929), Sec. C, 7(1), 062 - 070, 2016 - 17. 
Birnbaum Allan, On the Foundations of Statistical Inference, Journal of the American Statistical Association, Vol. 57, pp. 269 - 306, 1962.

Chakrabarty Dhritikesh, Determination of Parameter from Observations Composed of Itself and Errors, International Journal of Engineering Science and Innovative Technology, 3(2), (ISSN : 2139 - 5967), $304-311,2014 a$.

Chakrabarty Dhritikesh, Analysis of Errors Associated to Observations of Measurement Type, International Journal of Electronics and Applied Research (ISSN : 2395 - 0064), 1(1), 15 - 28, $2014 b$.

Chakrabarty Dhritikesh, Observation Composed of a Parameter and Chance Error: An Analytical Method of Determining the Parameter, International Journal of Electronics and Applied Research (ISSN : 2395 0064), 1(2), $20-38,2014 c$.

Chakrabarty Dhritikesh, Observation Consisting of Parameter and Error: Determination of Parameter, Proceedings of the World Congress on Engineering 2015, (WCE 2015, July 1 - 3, 2015, London, U.K.), ISBN: 978-988-14047-0-1, ISSN: 2078-0958 (Print); ISSN: 2078-0966 (Online), Vol. II, 680 - 684, $2015 a$.

Chakrabarty Dhritikesh, Central Tendency of Annual Extremum of Ambient Air Temperature at Guwahati, J. Chem. Bio. Phy. Sci. (E- ISSN : 2249 - 1929), Sec. C, 5(3), 2863 - 2877, $2015 b$.

Chakrabarty Dhritikesh, Central Tendency of Annual Extremum of Ambient Air Temperature at Guwahati Based on Midrange and Median, J. Chem. Bio. Phy. Sci. (E- ISSN : 2249 - 1929), Sec. D, 5(3), $3193-3204,2015 c$.

Chakrabarty Dhritikesh, Observation Composed of a Parameter and Chance Error: Determining the Parameter as Stable Range, International Journal of Electronics and Applied Research (ISSN : 2395 0064), 2(1), 35 - 47, 2015d.

Chakrabarty Dhritikesh, A Method of Finding True Value of Parameter from Observation Containing Itself and Chance Error, Indian Journal of Scientific Research and Technology, (E-ISSN: 2321-9262), $3(4), 14-21,2015 e$.

Chakrabarty Dhritikesh, Theoretical Model Modified For Observed Data: Error Estimation Associated To Parameter, International Journal of Electronics and Applied Research (ISSN : 2395 - 0064), 2(2), 29 $45,2015 f$.

Chakrabarty Dhritikesh, Impact of Error Contained in Observed Data on Theoretical Model: Study of Some Important Situations, International Journal of Advanced Research in Science, Engineering and Technology, (ISSN : 2350 - 0328), 3(1), 1255 - 1265, $2016 a$.

Chakrabarty Dhritikesh, Theoretical Model and Model Satisfied by Observed Data: One Pair of Related Variables, International Journal of Advanced Research in Science, Engineering and Technology, (ISSN : 2350 - 0328), 3(2), $1527-1534,2016 b$. 
Chakrabarty Dhritikesh, Numerical Data Containing One Parameter and Chance Error: Evaluation of the Parameter by Convergence of Statistic, International Journal of Electronics and Applied Research (ISSN : 2395 - 0064), 4(2), 59 - 73, 2017.

Chakrabarty Dhritikesh, Observed Data Containing One Parameter and Chance Error: Evaluation of the Parameter Applying Pythagorean Mean, International Journal of Electronics and Applied Research (ISSN : 2395 - 0064), 5(1), 32 - 45, 2018a. Online (http://eses.net.in/ESES Journal).

Chakrabarty Dhritikesh, Derivation of Some Formulations of Average from One Technique of Construction of Mean, American Journal of Mathematical and Computational Sciences, 3(3), 62 - 68, $2018 b$.

Chakrabarty Dhritikesh, One Generalized Definition of Average: Derivation of Formulations of Various Means, Journal of Environmental Science, Computer Science and Engineering \& Technology, Section C, (E-ISSN : $2278-179$ X), 7(3), $212-225,2018 c$.

Chakrabarty Dhritikesh, $f_{H}$ - Mean: One Generalized Definition of Average, Journal of Environmental Science, Computer Science and Engineering \& Technology, Section C, (E-ISSN : 2278 - 179 X), 7(4), $301-314,2018 d$. Also available in www.jecet.org.

Chakrabarty Dhritikesh, Generalized $f_{G}$ - Mean: Derivation of Various Formulations of Average, American Journal of Computation, Communication and Control, 5(3), 101 - 108, 2018e. Available in http://www.aascit.org/journal/ajmcs .

Cornelli G., McKirahan R. \& Macris C, On Pythagoreanism, Berlin, Walter de Gruyter, 2013.

de Carvalho Miguel, Mean, what do you Mean?, The American Statistician, 70, 764 -776, 2016.

George Marsagilia, Evaluating the Normal Distribution, Journal of Statistical Software, 11(4), 2004.

Ivory, On the Method of Least Squares, Phil. Mag., LXV, 3 - 10, 1825.

Kendall M. G. and Stuart A, Advanced Theory of Statistics, Vol. $1 \& 2,4^{\text {th }}$ Edition, New York, Hafner Press, 1977.

Kolmogorov Andrey, On the Notion of Mean, Mathematics and Mechanics, 199(1), 144 - 146, 1930.

Lehmann Erich L. \& Casella George (1998): Theory of Point Estimation, 2nd ed. Springer. ISBN 0 - 387 $-98502-6$.

Lucien Le Cam (1990): Maximum likelihood — An introduction, ISI Review, 58 (2), 153 -171.

Michiel ed. Hazewinkel (2001): Normal Distribution, Encyclopedia of Mathematics, Springer, ISBN 978 $-1-55608-010-4$. 
Walker Helen M. and Lev J., Statistical Inference, Oxford \& IBH Publishing Company, 1965.

O'Meara Dominic J., Pythagoras Revived: Mathematics and Philosophy in Late Antiquity, ISBN $\underline{\text { 0-19- }}$ 823913-0, Clarendon Press, Oxford, 1989.

Riedweg Christoph, Pythagoras: his life, teaching, and influence (translated by Steven Rendall in collaboration with Christoph Riedweg and Andreas Schatzmann, Ithaca), ISBN 0-8014-4240-0, Cornell University Press, 2005.

Walker Helen M. and Lev J. (1990): De Moivre on the Law of Normal Probability, In Smith, David Eugene, 1985. A Source Book in Mathematics, Dover, ISBN 0 - 486 - 64690 - 4, 2, 153 -171.

Wlodzimierz Brye (1995): The Normal Distribution: Characterizations with Applications", Springer Verlag, ISBN $0-387-97990-5$. 